\title{
Tumor de Células Gigantes em porção anterolateral de costela
}

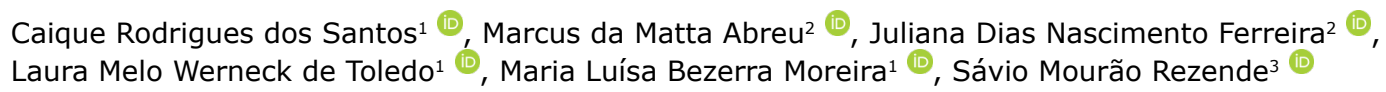

\section{RESUMO}

O Tumor de Células Gigantes é uma neoplasia osteolítica benigna, porém agressiva, ricamente vascularizada e com numerosas células gigantes com atividade osteoclástica. Ocorre mais frequentemente nas epífises de ossos longos e raramente acomete as costelas (cerca de $1 \%$ dos casos). A apresentação deste tumor em porção anterolateral de arco costal é extremamente rara em comparação com a região posterior. O presente relato descreve o caso de uma paciente que apresentava uma tumoração dolorosa em parede torácica anterolateral esquerda, de crescimento insidioso. Exames de imagem revelaram uma lesão insuflativa em $10^{\circ}$ arco costal esquerdo $(4,2 \times 3,5 \mathrm{~cm})$, com áreas de calcificação interior. A paciente foi submetida a tratamento cirúrgico, com ressecção ampla do tumor, englobando $9^{\circ}, 10^{\circ}$ e $11^{\circ}$ arcos costais e uma porção do diafragma. O diagnóstico definitivo de tumor de células gigantes se deu pela imunohistoquímica da peça cirúrgica. Este relato permite fornecer bases para o estudo das possibilidades terapêuticas desta patologia em localizações atípicas, reforçando que a exérese em bloco com margens amplas destes tumores promove uma menor chance de recidiva local.

Palavras-chave: Células gigantes, Costelas, Neoplasias ósseas, Parede torácica, Cirurgia torácica.

1. Universidade Federal de Juiz de Fora. Faculdade de Medicina. Juiz de Fora, (MG), Brasil

2. Universidade Federal de Juiz de Fora. Hospital Universitário. Departamento de Cirurgia Torácica. Juiz de Fora, (MG), Brasil.

3. Universidade Federal de Juiz de Fora. Hospital Universitário. Departamento de Ortopedia e Traumatologia. Juiz de Fora, (MG), Brasil 


\section{INTRODUÇÃO}

O Tumor de Células Gigantes (TCG) é uma neoplasia benigna de origem mesenquimal que representa $20 \%$ dos tumores benignos ósseos e $5 \%$ de todos os tumores ósseos primários. ${ }^{1-4} \mathrm{~A}$ incidência é maior em adultos jovens, sobretudo na terceira e quarta décadas de vida, com prevalência no sexo feminino. ${ }^{5}$ Ocorre mais frequentemente nas epífises de ossos longos e raramente acomete as costelas (cerca de $1 \%$ dos casos). ${ }^{6,7} \mathrm{~A}$ apresentação do TCG em porção anterolateral de costela é ainda mais rara em comparação com o arco posterior e o tubérculo costal. 2,3,4,7

Embora seja considerado uma neoplasia benigna, o tumor de células gigantes pode apresentar comportamento localmente agressivo, com invasão de partes moles adjacentes, altas taxas de recorrência após o tratamento, e, em casos raros (2\%), metástases à distância, geralmente pulmonares. ${ }^{1-2 ; 5-7}$ Quando presente, a metástase pulmonar do TCG apresenta características histológicas indolentes, similares às do TCG primário, e podem, inclusive, regredir espontaneamente. ${ }^{1,5,7}$ Apesar de ser frequentemente confundido com neoplasias malignas por apresentar agressividade local, o TCG raramente sofre transformação maligna. ${ }^{1-3 ; 5-6}$

Neste relato, descrevemos um caso raro de TCG em porção anterolateral de costela, aprovado pelo Comitê de Ética em Pesquisa com Seres Humanos HU-UFJF sob o Parecer no 4.341.895, cujo diagnóstico foi obtido por análise anatomopatológica e imunohistoquímica após a ressecção cirúrgica do tumor com margens de segurança oncológica. Este estudo acrescenta à literatura informações sobre a apresentação do TCG em porção anterolateral de costela, tendo em vista a raridade do caso e o pequeno número de publicações sobre o tema. O objetivo do trabalho é fornecer bases para o estudo das possibilidades terapêuticas para o TCG agressivo de costela, reforçando a ressecção cirúrgica em bloco com margens amplas como conduta mais segura para prevenir recorrência da neoplasia, metástases à distância e transformação maligna. ${ }^{3,6,7}$

\section{RELATO DE CASO}

Paciente do sexo feminino, 38 anos, tabagista (aproximadamente 10 anos-maço), atendida no ambulatório de Cirurgia Torácica do Hospital Universitário da Universidade Federal de Juiz de Fora, com relato de abaulamento em parede torácica esquerda, com crescimento há aproximadamente dois anos, associado a dor, que limitava algumas posturas. Negava febre ou perda de peso. Ao exame físico, apresentava tumoração de consistência fibroelástica e aderida a planos profundos em parede lateral do hemitórax esquerdo, dolorosa à palpação.

Foi realizada uma Radiografia de Tórax (RX) que evidenciou uma lesão óssea lítica e excêntrica em $10^{\circ}$ arco costal esquerdo. A Tomografia Computadorizada (TC) de tórax (Figura 1) revelou a presença de uma lesão insuflativa lateral em $10^{\circ}$ arco costal esquerdo, medindo $4,2 \times 3,5 \mathrm{~cm}$, com áreas de calcificação interior. A Cintilografia Óssea (Figura 2) mostrou atividade osteogênica em $10^{\circ}$ arco costal esquerdo, sugestiva de lesão primária. Exames laboratoriais sem alterações.

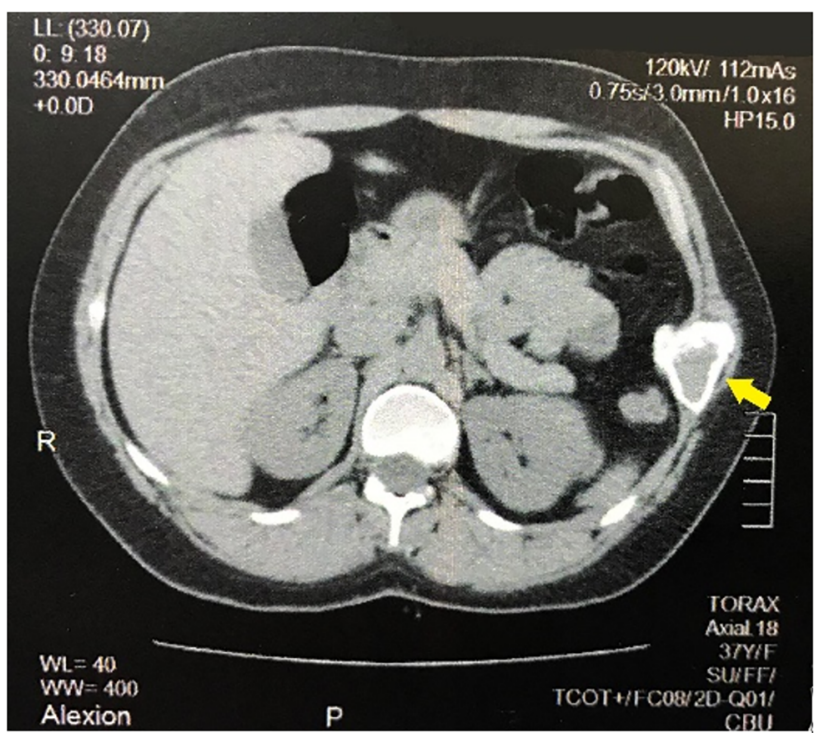

Figura 1. TC de tórax evidenciando lesão insuflativa em $10^{\circ}$ arco costal esquerdo (seta amarela).

Diante dos achados, optou-se pela realização de tratamento cirúrgico, com ressecção ampla do tumor, englobando $9^{\circ}, 10^{\circ}$ e $11^{\circ}$ arcos costais a esquerda e parte do diafragma (Figura $3 \mathrm{~A}$ ), que se encontrava invadido pela lesão. O reparo da parede torácica foi feito com sutura da musculatura, sem necessidade de uso de prótese (Figura 3B). O pós-operatório transcorreu sem intercorrências, e a paciente recebeu alta em quatro dias.

A Peça Cirúrgica (Figura 4) foi enviada para a realização de exame Anatomopatológico, que revelou a presença de uma proliferação de células ovoides com mínimas atipias, permeadas por numerosas células gigantes multinucleadas osteoclasto-like, características sugestivas de Tumor de Células Gigantes (TCG) Ósseo. A confirmação diagnóstica de TCG se deu pela Imunohistoquímica, ao evidenciar a presença dos Anticorpos Histona H3.3 G34W e SATB2 nas células Estromais e do Anticorpo CD68 nas células multinucleadas. 


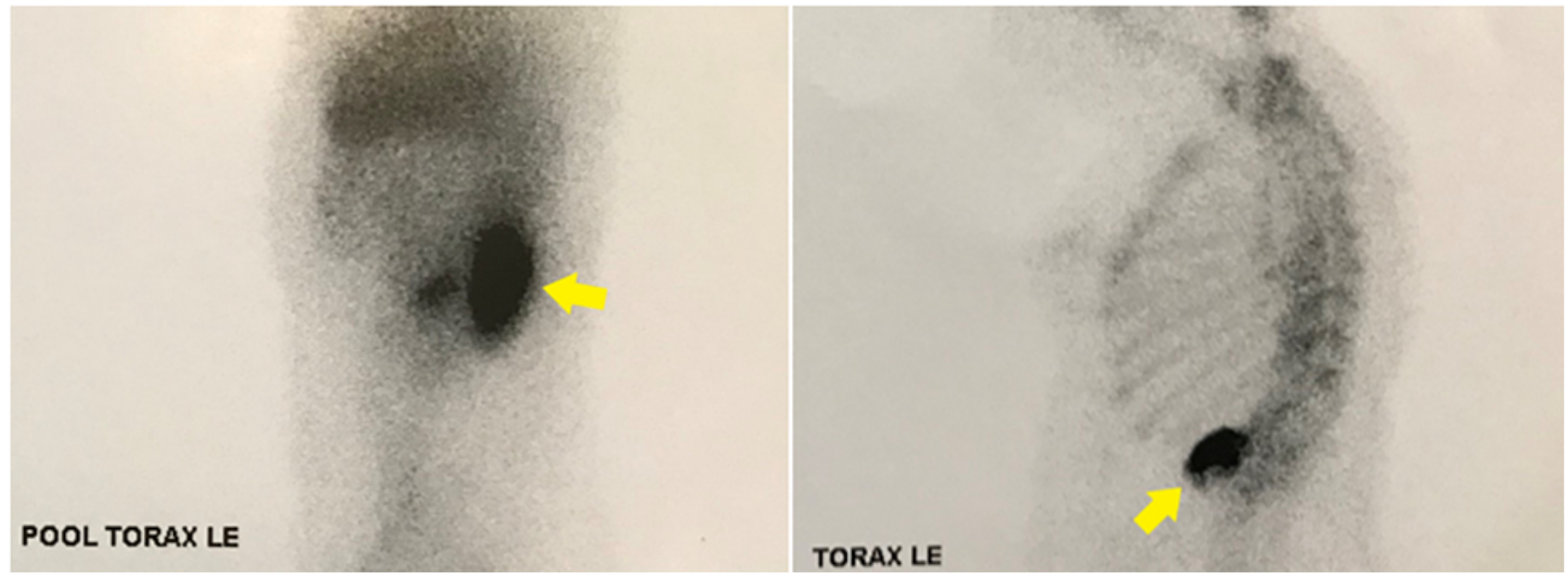

Figura 2. Cintilografia Óssea revelando atividade osteogênica em $10^{\circ}$ arco costal esquerdo (setas amarelas).

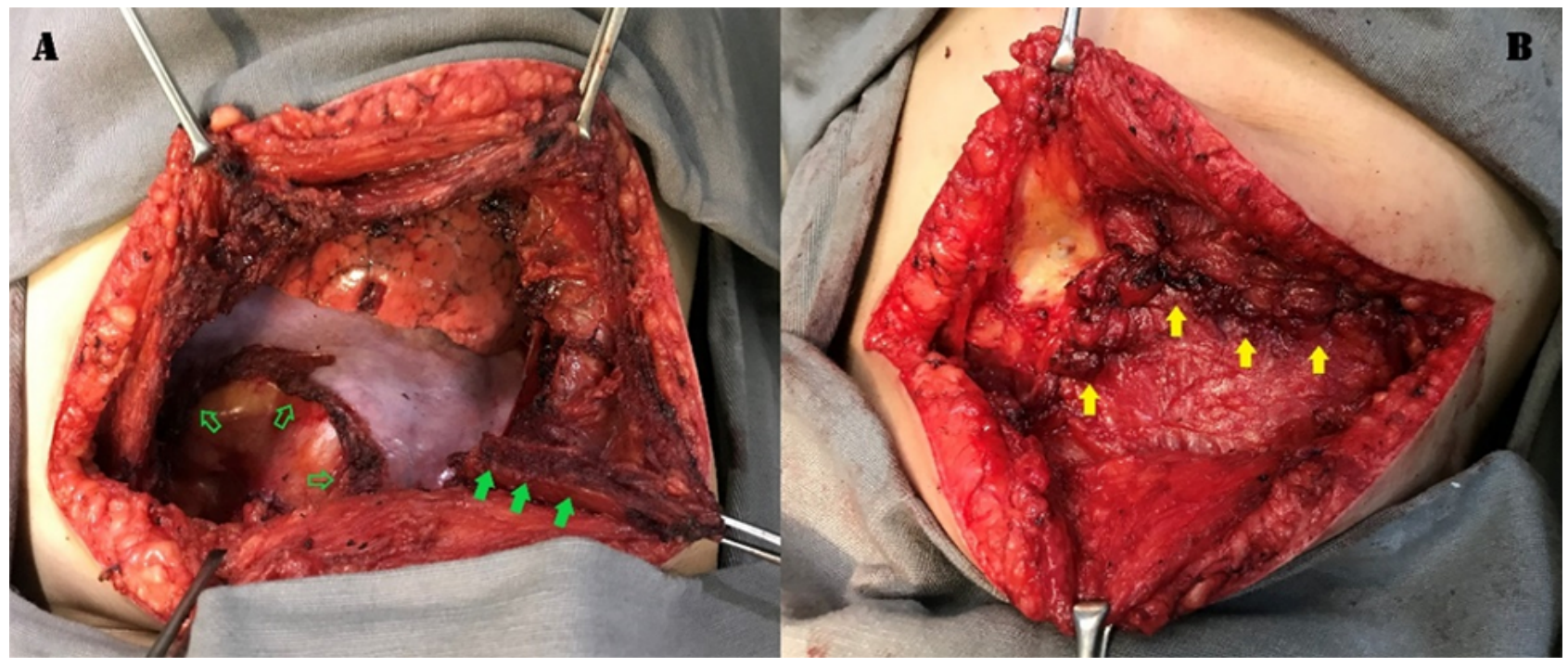

Figura 3A: Toracotomia mostrando parte do diafragma ressecado (setas verdes vazias), após a ressecção ampla do tumor (setas verdes cheias). B: Reparo da parede torácica, com reconstrução do diafragma e sutura da musculatura (setas amarelas).

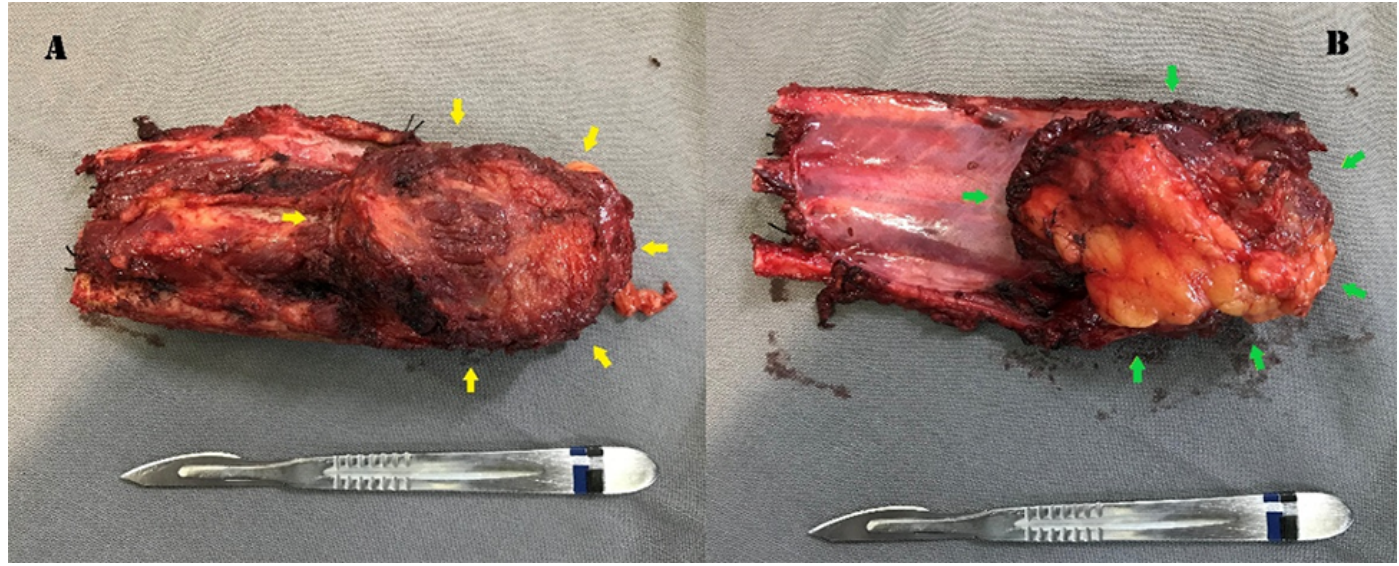

Figura 4. Peça cirúrgica. A: Porção externa ao gradil costal (setas amarelas). B: Porção intratorácica (setas verdes). 
Paciente segue em acompanhamento ambulatorial, sem evidência de recidiva da doença após 12 meses.

\section{DISCUSSÃO}

O Tumor de Células Gigantes (TCG) é uma neoplasia esquelética osteolítica benigna, porém agressiva, ricamente vascularizada e com numerosas células gigantes com atividade osteoclástica. ${ }^{8} \mathrm{Em}$ $90 \%$ dos casos possuem localização epifisária típica em ossos longos, principalmente fêmur distal, tíbia proximal e rádio distal. ${ }^{7,10}$ Devido à raridade do TCG em topografia atípica, seu diagnóstico definitivo torna-se extremamente difícil de ser realizado antes de uma conduta terapêutica. ${ }^{10,11}$

De acordo com a literatura, exames complementares como Radiografia Simples (RX), Tomografia Computadorizada (TC) e Ressonância Magnética (RM) evidenciam uma lesão óssea lítica, excêntrica, com afilamento cortical ou até ruptura cortical com extensão aos tecidos moles adjacentes. ${ }^{10} \mathrm{~A}$ presença de calcificação na matriz é rara. ${ }^{3} \mathrm{O}$ RX de tórax e a TC de tórax desta paciente evidenciaram uma lesão óssea insuflativa lateral em $10^{\circ}$ arco costal esquerdo com áreas de calcificação na matriz. O achado da Cintilografia óssea foi compatível com relatos da literatura, na qual a TCG apresenta hipercaptação local pelo aumento da atividade osteoblástica reacional. ${ }^{5}$

Estudos recentes têm sugerido o uso da Fosfatase ácida sérica (ACP) como marcador útil para diagnóstico de Tumor de Células Gigantes (TGC) e seguimento do paciente. ${ }^{11}$ De acordo com Goto et al. ${ }^{11}$, sua elevação se deve à secreção ou liberação a partir das células gigantes do tumor.

O diagnóstico diferencial deve incluir Cistos Ósseos Aneurismáticos, Fibroma não exsudativo, Osteossarcoma, Condroblastoma, Tumores Marrons associados ao Hiperparatireoidismo e Câncer metastático. ${ }^{8} \mathrm{O}$ diagnóstico diferencial não foi obtido no pré-operatório devido à baixa especificidade apresentada nas punções aspirativas em tumores ósseos de parede torácica. ${ }^{5}$

O tumor de células gigantes deve ser classificado de acordo com as classificações de Campanacci e de Enneking. ${ }^{8}$ Nossa paciente foi classificada como Campanacci Grau III (Quando cursa com lesões extraósseas que rompem o córtex e se estendem para os tecidos moles adjacentes) e Enneking Estágio III (Quando cursa com a presença de tumores altamente vascularizados e agressivos), devido à ruptura cortical e extensão para as partes moles adjacentes. ${ }^{8} \mathrm{O}$ padrão-ouro de tratamento para pacientes com essa classificação é a resseção cirúrgica agressiva (em bloco) da lesão com margens amplas de segurança oncológica, envolvendo o osso e as partes moles adjacentes, conforme realizado. ${ }^{7}$ Vários estudos sugerem que este procedimento reduz consideravelmente o risco de recidiva local quando comparado à curetagem intralesional associada a cimentação, tratamento dos TCGs em topografias típicas e classificações I ou II de Campanacci e Enneking. ${ }^{3,7}$ Neste caso, foi ressecado ainda uma porção do diafragma que apresentava invasão tumoral. O diafragma foi reconstruído através de sutura com fio de PDS 0 , sem necessidade de utilização de próteses.

O tratamento radioterápico para o TCG é ainda muito controverso. Há relatos de que a maioria das transformações malignas existentes no TCG estão associadas à radioterapia prévia. ${ }^{3,7,11}$

Para pacientes com doença irressecável e localmente recorrente, as opções incluem Denosumabe, radioterapia ou embolização arterial. ${ }^{8}$ Vale ressaltar que o Denosumabe como adjuvante em outros casos é bastante discutível ainda, merecendo mais estudos confirmatórios. ${ }^{8}$

\section{CONCLUSÃO}

Este relato permite ampliar as bases literárias acerca da principal modalidade terapêutica aplicada ao Tumor de Células Gigantes Ósseo, ao reforçar que a exérese em bloco com margens amplas, considerada padrão-ouro nos Tumores de Células Gigantes em localizações típicas, também promove uma menor chance de recidiva local quando em localizações atípicas, evidenciado pela ausência de recidiva no seguimento clínico da paciente.

\section{REFERÊNCIAS BIBLIOGRÁFICAS}

1. Chakarun CJ, Forrester DM, Gottsegen CJ, Patel DB, White EA, Matcuk GR. Giant Cell Tumor of Bone: Review, Mimics, and New Developments in Treatment. Radiographi. 2013; 33(1): 197-211.

2. Park HL, Yoo IR, Lee Y, Park SY, Jung CK. Giant Cell Tumor of the Rib: Two Cases of F-18 FDG PET/CT Findings. Nucl Med Mol Imaging. 2016; 51(2): 182-5. 
3. Sharma A, Armstrong AE. Giant Cell Tumor of Rib Arising Anteriorly as a Large Inframammary Mass: A Case Report and Review of the Literature. Case Rep Med. 2012; 2012: 850509. DOI: 10.1155/2012/850509.

4. Manjunatha HK, Ramaswamy AS, Kumar BS. Aggressive giant cell tumor of the anterior arc of the rib. J Cytol. 2012; 29(1): 51-3. DOI: 10.4103/0970-9371.93224.

5. Cordeiro AZB, Cordeiro PB, Sousa AMC, Lannes DC, Pierro GSM. Tumor de células gigantes costal ocupando todo o hemitórax. J Bras Pneumol. 2008; 34(3): 185-8. DOI: 10.1590/S1806-37132008000300010.

6. Shenoy R, Dewan RK, Saxena R, Ganapathi A. Giant cell tumor of rib presenting as intra-thoracic mass: a rare case report. Indian J of Thorac Cardiovasc Surg. 2016; 33(1): 45-7.

7. Kamal AF, Setiawan E, Wardoyo S. Gigantic giant cell tumor of the anterolateral rib treated with wide resection. Formos J Surg. 2019; 52(5): 183-8. DOI: 10.4103/fjs.fjs_28_19.

8. Thomas DM, Desai J, Damron TA. Giant cell tumor of bone. UpToDate [Internet]. 2020 [cited 2020 Jul 20]. Available from: https://www.uptodate.com/contents/ giant-cell-tumor-of-bone?search=tumor $\% 20 \mathrm{de} \% 20$ celulas $\% 20$ gigantes\&source $=$ search_result\&selectedTi $\mathrm{tle}=1 \sim 150 \&$ usage_type $=$ default\&display_rank=1\# H1.

9. Filho RJG. Tumores ósseos e sarcomas dos tecidos moles. Einstein (São Paulo). 2008; 6(Supl 1): S102-S19.

10. Moschouris $H$, Marinis A, Bouma E, Karagiannis $E$, Kiltenis M, Papadaki M. Nonepiphyseal Giant Cell Tumor of the Rib: A Case Report. Case Rep Oncol Med. 2012; 2012: 745292. DOI: 10.1155/2012/745292.

11. Heo W, Kang DK, Min HK, Jun HJ, Hwang YH. Giant Cell Tumor Arising from Anterior Arc of the Rib. Korean J Thorac Cardiovasc Surg. 2013; 46(5): 377-9. DOI: 10.5090/kjtcs.2013.46.5.377. 
Autor correspondente:

Caique Rodrigues dos Santos

caiquerodriguesds@gmail.com

Editor:

Prof. Dr. Paulo Henrique Manso

Recebido: 28/10/2020

Aprovado: 27/05/2021 